\title{
The Relationship Between Students' Achievement in Junior Secondary Physical and Health Education and Senior Secondary Physical Education
}

\author{
Lawrence Achimugu \\ Department of Science Education, Kogi State University, Anyigba, Nigeria
}

\section{Email address:}

Lawachi88@gmail.com

\section{To cite this article:}

Lawrence Achimugu. The Relationship Between Students' Achievement in Junior Secondary Physical and Health Education and Senior Secondary Physical Education. Teacher Education and Curriculum Studies. Vol. 2, No. 4, 2017, pp. 47-51. doi: 10.11648/j.tecs.20170204.12

Received: June 2, 2017; Accepted: June 23, 2017; Published: July 31, 2017

\begin{abstract}
This study examines the extent to which scores obtained by students at the Basic Education Certificate Examination (BECE) in Physical and health education (PHE) conducted by Kogi State ministry of education predict the scores obtained by the same students at the senior Secondary Certificate Examination (SSCE) in Physical education (PE) conducted by National Examination Council (NECO) in Lokoja metropolis, Nigeria. The study adopted an ex-post - facto research design. One research question as well as one hypothesis guided the study. The sample size was 450 students who participated in 2013 BECE and 2016 SSCE from five senior secondary schools selected by simple random sampling technique from the total population of 32 senior secondary schools in Lokoja metropolis. The instrument used for data collection was proformatitled students' achievement records in BECE and SSCE (SARBS). The data was analysed using Pearson's product moment correlation coefficient to answer research question and $t$ - test of significant of relationship to test the hypothesis at 0.05 level of significance. The results indicated that there was no significant relationship between scores obtained by students in physical and health education at the BECE and scores obtained by the same students in physical education at the SSCE. It was recommended among others that more physical education topics should be included in PHE curriculum and PHE teachers should be given adequate training.
\end{abstract}

Keywords: Relationship, Students' Achievement, Physical and Health Education, Physical Education, Basic Education Certificate Examination, Senior Secondary Certificate Examination

\section{Introduction}

\subsection{Background of the Study}

In response to attainment of the Millennium Development Goals (MDGs) and the critical targets of the national economic empowerment and development strategies (NEEDS), the Federal Government of Nigeria, came out with the need to review and restructure the existing curricular of primary and secondary schools to fit into 9-year basic education programme and post-basic education. In selecting the contents, three major issues shaping the development of nation worldwide were identified, namely: globalization, information technology (IT) and entrepreneurship education. The recipient of the education would spend 9- years. i.e 3 years in primary; 3 years in middle primary and 3 years in junior secondary schools. That is to say 6 years in primary school and 3 years in junior secondary school. To transit from the 9 years education programme to the 3 years senior secondary school, involves taking the basic education certificate examination (BECE) which replaced Junior school certificate examination (JSCE) in the third year of the junior secondary school. BECE is conducted by each state of the federation, including Federal Capital Territory, Abuja through their respective ministries of education for public and private secondary schools. The National Examination Council (NECO) conduct the BECE for all the federal government colleges (unity schools) and any other interested secondary schools. Presently, the study is focused on BECE conducted by Kogi State ministry of education (KSMOE). A candidate is expected to sit for a minimum of ten subjects and a maximum of 14 subjects. A candidate is deemed to have passed the BECE, if he/she has six credits pass in six subjects including mathematics, English language. This study focused 
on BECE conducted on physical and health education for junior secondary school in Kogi State.

Physical and health education has been grouped as a core subject at the Junior secondary school. One of the main objectives of the curriculum is to enable learners to become prepared for further studies in physical education as well as health education at the senior secondary school level. The content of the curriculum reveals major theme which provides basis for further studiesin physical and health education. This study focus on the relationship between students' achievement in Junior secondary physical and health education (PHE) and senior physical education (PE).

[1] defined physical education as an essential part of general education which has its aims at the development of physically, mentally, emotionally and socially fit citizens through medium of physical activities which have been selected with the view of realizing the outcomes. According to [2], physical education is the art and science of voluntary and purposeful human movement involving wide range of physical activities. Physical education can therefore be defined as that aspect of education that aims at the physical, mental and emotional health of an individual among others. [3] pointed out that as a subject that combines theory and practice, the availability and functionality of sports facilities are essential for effective teaching and learning physical education and sports in schools. At senior school level, physical education is grouped among the science subjects as an elective. According to the [4], the theme of senior secondary school curriculum for physical education include: foundation of physical education and sports; National and International sports competitions; Basics human anatomy and physiology in relation to physical activities; theory and practice of athletics and dances; and physical fitness and conditioning. The physical and health education (PHE) content which the Junior secondary school students learn is expected to lay a foundation for the students' at the senior secondary physical education. Therefore, it is speculated that achievement in BECE physical and health education would positively predict students' achievement in senior secondary school certificate examination (SSCE) in physical education. There are presently two bodies that conduct SSCE namely: West African Examination Council (WAEC) and National Examination Council of Nigeria (NECO). Presently, the study is focused on SSCE conducted by NECO (i.e NECO SSCE). According to [5] NECO was established by the Federal Government of Nigeria in April, 1999 to relieve WAEC of some obvious burdens and aimed at having an examination body that is parallel but of the same standard as WAEC. NECO has its headquarter at Minna and she conducts mainly BECE for Federal Government Colleges and NECO SSCE/NECO - GCE for all the senior secondary students in Nigeria. A careful observation of the researcher has shown that students who passed BECE at a credit level do fail NECO - SSCE in some subjects.

Many studies have been carried out on the effects of examination results in the lower level of education predicting examination results at the higher level of education. A study by [6] on the correlation between qualifying examination (QE) and senior secondary certificate examination (SSCE) in biology in Kano, revealed that there was a positive correlation between qualifying examination and senior secondary certificate examination in biology. A study by [7] on the relationship between students performance in junior secondary mathematics and senior secondary mathematics, further mathematics and physics revealed that a positive relationship between JSS mathematics and SS mathematics further mathematics and physics. [8] carried out a study on the relationship between students' achievement in senior secondary certificate examination (SSCE) and Junior school certificate examination (JSCE) mathematics in On do State, Nigeria and revealed that there was significant positive relationship between the two examinations. Also study by [9] on comparative study of the predictive validities of students performance at the senior certificate mathematics from junior certificate scores in Delta and Edo States, Nigeria showed that there is significant relationship between scores obtained by students in mathematics of the JSCE and the score obtained in the same subject at the SSCE.

In sharp contrast, study by [10] investigated the comparative study of students performance in SSCE mathematics and pre-National Diploma (Pre-ND) programmes in mathematics and the results showed that there was no correlation between SSCE - NECO mathematics and Pre-ND mathematics. Similarly, a study by [11] on predictive validity of Ogun State Junor secondary certificate examination (JSCE) showed that Ogun State JSSCE is a poor predictor of students' performance in SSCE except for mathematics and English Language. From the above, Literature review the issue of examination results in lower level predicting examination results in high level remain controversial and inconclusive. Furthermore, not much work have been done on the recently introduced Basic education certificate examination (BECE) that replaced the Junior school certificate examination (JSCE) as well as physical education as a subject. Hence, the need to find out the relationship of Kogi State ministry of education - Basic education certificate examination in physical and health education (PHE) on the National examination council Senior Secondary certificate examination in physical education.

\subsection{Statement of the Problem}

As a result of a high failure rate in senior secondary certificate examination in physical education at the senior secondary school, a great importance was attached to effective teaching and learning of physical and health education at the Junior secondary school in other to lay a good foundation at that level of education. [12] theory of learning provided the theoretical framework of this thought, when he pointed out that meaningful learning takes place when there is an appropriate link between prior knowledge and new body of knowledge. In other words learning of any new ideas or concepts in physical education depends upon the mastery of the prerequisite ideas or concepts in physical 
and health education. It was assumed that students who pass PHE at credit level in BECE at the junior secondary school level will still pass PE at credit level in SSCE at the senior secondary school level. This assertion is to be proved. It is on this premise that the researcher sought to investigate the relationship between the students' achievement in junior secondary physical and health education and senior secondary physical education. And in the process, find out the predictive validity of BECE physical and health education on SSCE physical education in Lokoja metropolis.

\subsection{Purpose of the Study}

The main purpose of this study is to ascertain the extent to which scores obtained by students at the Basic Education Certificate Examination (BECE) in Physical and Health Education (PHE) conducted by Kogi State Ministry of Education predict the scores obtained by the same students at the senior Secondary Certificate Examination (SSCE) in Physical Education (PE) conducted by National Examination Council (NECO)

\subsection{Research Question}

What is the relationship between students' academic achievement in physical and health education BECE conducted by Kogi State ministry of education and physical education SSCE conducted by National examination council?

\subsection{Hypothesis}

Ho: there is a significant relationship between scores obtained by students in physical and health education at the BECE and scores obtained by the same students in physical education (PE) at the SSCE

\section{Method}

The study adopted ex-post-facto design. The design was used because the event has already taken place. For instance, the students have already taken BECE and SSCE. The population of the study comprised of the students who sat for the KSMOE - BECE in 2013 and the version of NECO SSCE in 2016 in Lokoja metropolis. And there are32 public and privatesenior secondary schools in Lokoja metropolis as at May 2017 with the estimated population of 3,200 students who sat for the two examinations. Five senior secondary schools were selected by simple random sampling technique by balloting. All the students who sat for the KSMOE BECE in 2013 and NECO - SSCE in 2016 from the five secondary schools constituted the sample and there were 450 .

The instrument that was used to collect data from exam officers' offices of the selected senior secondary schools was a proforma titled "Students' achievement records in BECE and SSCE (SARBS)". Since KSMOE - BECE and NECO SSCE are valid and reliable documents, there was no need for any other validation or reliability assessment exercise. Thus, the instruments used for this study were valid and reliable. Since the valid scores/grades of Kogi State ministry of education - BECE differs from national examination council SSCE interval scores/grades, there was a need to match them and assign a numerical range that will enable comparison of their achievement. The matching pattern and the numerical points are shown in table 1.

Table 1. Matching of BECE/SSCE Scores and Their Assigned Values.

\begin{tabular}{lllll}
\hline BECE & SSCE & $\begin{array}{l}\text { Score } \\
\text { Intervals }\end{array}$ & Pattern & $\begin{array}{l}\text { Assigned } \\
\text { Values }\end{array}$ \\
\hline $\mathrm{A}$ & $\mathrm{A}_{1}$ and $\mathrm{B}_{2}$ & $70-100$ & $\mathrm{~A}$ & 5 \\
$\mathrm{~B}$ & $\mathrm{~B}_{3}$ and $\mathrm{C}_{4}$ & $60-69$ & $\mathrm{~B}$ & 4 \\
$\mathrm{C}$ & $\mathrm{C}_{5}$ and $\mathrm{C}_{6}$ & $50-59$ & $\mathrm{C}$ & 3 \\
$\mathrm{D}$ & $\mathrm{D}_{7}$ and $\mathrm{E}_{8}$ & $40-49$ & $\mathrm{D}$ & 2 \\
$\mathrm{E} \& \mathrm{~F}$ & $\mathrm{~F}$ & $0-39$ & $\mathrm{E}$ & 1 \\
\hline
\end{tabular}

The data was analysed using pearson's product moment correlation coefficient to answer the research question and $\mathrm{t}-$ test of significance of relationship to test the hypothesis at 0.05 level of significance.

\section{Results and Discussion}

\subsection{Results}

\subsubsection{Research Question}

What is the relationship between scores obtained by students in physical and health education (PHE) at BECE and the scores obtained by the same students in physical education (PE) at the SSCE?

Table 2. Relationship Between BECE in Physical and Health Education (PHE) and SSCE in Physical Education.

\begin{tabular}{lllll}
\hline Exams & $\mathbf{N}$ & $\overline{\mathbf{X}}$ & SD & r-value \\
\hline BECE X & 450 & 2.63 & 0.58 & 0.16 \\
SSCE Y & 450 & 2.55 & 0.61 & \\
\hline
\end{tabular}

From table 2, the result shows that the pearson's product moment of coefficient $(r)=0.16$. From the result, there is a very low correlation between the scores of the students in Physical and Health Education in BECE and their scores in Physical Education in SSCE. This means that students who passed KSMOE-BECE in PHE have very low probability of passing PE in NECO-SSCE and vice visa.

\subsubsection{Hypothesis}

Ho: There is significant relationship between scores obtained by students in physical and health education at the BECE and the scores obtained by the same students in physical education at the SSCE.

Table 3. T - Test of Significant of Relationship Between Students Achievement in Physical and Health Education BECE and Physical Education SSCE.

\begin{tabular}{llclllll}
\hline Variable & $\mathbf{N}$ & $\overline{\mathbf{X}}$ & SD & $\mathbf{r}$ & Df & t-cal & t-table \\
\hline BECE & 450 & 2.63 & 0.58 & 0.16 & 898 & 0.977 & 1.98 \\
SSCE & 450 & 2.55 & 0.61 & & & & \\
\hline
\end{tabular}

Table 3 shows that the calculated t-value of 0.977 is less than the table value of 1.98 at 898 degree of freedom. This means that the hypothesis is not rejected implying that there 
was no significant relationship between the achievement scores of students in BECE physical and health education and SSCE physical education. Thus, students who passed BECE in physical and health education have low probability of passing physical education at the senior secondary certificate examination and vice-versa. This implies that KSMOE-BECE in PHE is not a good predictor of later achievement in PE at NECO-SSCE

\subsection{Discussion}

From table 2, the results of the investigation showed that there was a very low relationship between the scores of the students in KSMOE-BECE in Physical and Health Education and NECO-SSCE in Physical Education. This finding is in line with [13] 5-ways of Pearson's product moment correlation coefficient interpretation guide which considered any r-value between $0.00-0.20$ as very low. Thus, the very low relationship obtained showed that students who passed KSMOE-BECE in Physical and Health Education have very low probability of passing physical Education in NECOSSCE and vice visa. The finding of this study corroborates with that of [11] who found out that the relationship between the Ogun state Junior Secondary Certificate Examination (JSCE) and Senior Secondary Certificate Examination (SSCE) except for mathematics and English language were low. The result obtained could have been as a result of fact that the curriculum content of Physical Education in the Physical and Health Education at the Junior Secondary School is also low. This makes the students not to have good foundation at the later topics in Physical Eduation at the Senior Secondary School level and hence the low relationship between BECE -PHE and SSCE -PE.

The results of this study further revealed that there was no significant relationship between achievement scores obtained by students in physical and health education at the BECE and the scores they obtained in physical education at the SSCE. In other words, the relationship between the achievement of students in the two examinations is indirectly proportional to each other (i.e decrease in one will bring the increase in the other or increase in one will bring decrease in the other). This also means that Kogi State ministry of education - BECE in physical and health education is a poor predictor of students' achievement at National examination Council - SSCE in physical education. The finding of this study is in conformity with the finding of [10] who found that Osun State JSSCE is a poor predictor of students' performance in SSCE in all subjects except English Language and Mathematics. However the work contradict the growing evidence in Literature ([14]; [6]; [8]; [15]; [16] and [9]) that JSSCE scores were good predictors of scores by students at the SSCE. The surprising outcome of the present study may be as a result of the fact that the physical education content of the physical and health education are too few to give prospective physical education students sound foundation at the Junior secondary school level. A careful observation of the physical and health education contents in the Junior secondary school curriculum shows that the content is dominated by health education aspect of the health aspect of the PHE curriculum.

\section{Conclusion}

The study concludes that Kogi State Ministry of Education - BECE in physical and health education (PHE) is a poor predictor of students' achievement in National Examination Council - SSCE in physical education (PE). That is to say, that the predictor variable (KSMOE - BECE physical and health education) do not correlate significantly with the criterion - variable (NECO - SSCE physical education).

\section{Recommendations}

Based on the findings of this study, the following recommendations were made:

(1) Curriculum planners should review the physical and health education (PHE) curriculum so as to include more physical education (PE) topics in the PHE curriculum.

(2) Physical and health education teachers should try as much as possible to relate the curriculum content of physical and health education in the junior secondary school to the curriculum content of physical education in the senior secondary schools.

(3) Government should endeavour to employ qualified teachers to effectively handle both physical and health education and physical education at both the junior and senior secondary schools respectively.

(4) Physical and health education teachers should be trained on the requirement of physical and health education curriculum so as to ensure proper implementation of physical and health education curriculum at the Junior secondary schools.

(5) Further investigation should be carried out on the evaluation of curriculum content of Physical and Health Education so as to determine the baseline content that will enhance achievement of student at the Senior Secondary Physical Education.

(6) More correlation studies should be conducted in other to ascertain the extent to which BECE predicts students' achievement in SSCE in all subjects offered at the Junior and Senior Secondary Schools.

\section{References}

[1] Kayode, A. (2007). A survey of the availability of facilities and equipment for the teaching of physical education (PE) \& Sports in secondary schools in River State. In U. Nzewi (Ed), $50^{\text {th }}$ Annual conference Proceedings of Science Teachers Association of Nigeria (STAN), 204 - 215, Ibadan, HEBN Publishers Plc.

[2] Nixon, J. E. \& Jewett, A. E. (1980). An introduction to physical education $9^{\text {th }}$ edition, philadelpha - USA, Saunders College. 
[3] Adesanya, O. A. (1992). Administration and management of physical education and sports. Lagos, Florence.

[4] Federal Ministry of Education (2012). Senior Secondary School Curriculum physical education, Abuja: Nigeria Educational Research and Development Council (NEDRC) Press.

[5] Olarewaju, C. A. (2007). Correlation between students' grades in Home Economics in WAEC and NECO examinations in $2003 / 2004$ and 2004/2005 academic session. In U. Nzewi (Ed), $50^{\text {th }}$ Annual conference Proceedings of Science Teachers Association of Nigeria (STAN), 143 - 149, Ibadan, HBEN, Publishers Plc.

[6] Dogara, M. M. (2002). The correlation between qualifying examination $(\mathrm{QE})$ and senior secondary school certificate examination (SSCE) in Kano metropolis. Journal of science teachers' association of Nigeria, 37, (1 \& 2), 51 - 57.

[7] Ifamuyiwa, S. A. (2004). The relationship between students' performance in Junior secondary mathematics and senior secondary mathematics, further mathematics and physics. In M. A. G. Akale (Ed), $45^{\text {th }}$ Annual conference Proceedings of Science Teachers' Association of Nigeria (STAN), 166 - 169, Ibadan: HEBN PublishersPlc.

[8] Adeyemi, T. O. (2008). Predicting students' performance in senior secondary certificate examination from performance in Junior secondary certificate examination in Ondo State, Nigeria. Humanity and social science Journal, 3, (1), 26 - 36.

[9] Orubu, M. E. N. (2015). A comparative study of the predictive validities of students' performance at senior certificate mathematics for junior certificate scores in Delta and Edo States, Nigeria. Nigerian Journal of Educational Research and Evaluation, 14, (3), 181 - 190.

[10] Samuel, H. T. (2012). A comparative study of performance in SSCE mathematics and pre-National Diploma (Pre-ND) programmes in mathematics. Journal of education and practice, 4, (27), $25-27$.

[11] Falaye, B. A. \& Afolabi, E. R. (2005). Predictive Validity of Osun State Junior Secondary Certificate Examinations. Electronic Journal in Education Psychology, 5, (1), 131 - 144.

[12] Ausubel, D. P. (1970). Educational Psychology; cognitive view, New York; Holt, Rinehart and wiston.

[13] Nwana, O. C. (1999). Introduction to educational Research, Ibadan, Heinemann Educational books (NIG) Ltd.

[14] Adeyemi, T. O. (1998). School and Teacher variables associated with the performance of students in the senior secondary certificate examinations in Ondo State, Nigeria. Unpublished Ph. D Thesis, University of Hull, United Kingdom.

[15] Osadebe, P. U. (2003). Predictive validity of junior secondary certificate examination for senior secondary school. Journal of Educational Research \& Development, 2, (1), 183 - 186.

[16] Ugwuda, S. O. \& Abonyi, O. S. (2013). Predictive validity of NECO Junior certificate examination on students' achievement in NECO senior school certificate examination. Journal of Science Teachers Association of Nigeria, 48, (1), $78-95$. a. 